\title{
APUNTES SOBRE LAS DIVERSAS EDICIONES DE EL SEÑOR PRESIDENTE
}

Uno de los problemas con que se enfrenta el crítico de la literatura española e hispanoamericana actual es la disponibilidad de varias ediciones de la misma obra, ninguna de las cuales puede considerarse la definitiva. El porqué es, tal vez, obvio. En primer lugar, dado el descuido de muchas editoriales, es rara la edición sin errores tipográficos que, por razones lingüísticas, no siempre pueden reconocerse como tales. Es bastante común también que un autor cambie o corrija su obra entre una edición y otra sin que el hecho quede anotado en el texto mismo. Por último, siempre hay la posibilidad de la censura, si no por un censor «oficial», por lo que se ha llamado un "corrector de estilo» ${ }^{1}$.

Sin saber precisamente dónde termina la mano del autor y dónde empieza la del transcriptor, del corrector de pruebas o del censor, el crítico puede optar por lo más fácil: considerar que cualquier edición es la definitiva. En su estudio sobre «Maya Quiché Sacred Myth in Asturias' novel El Señor Presidente», William Myron Davis nos convence del peligro que hay en esta tendencia. En una extensa nota sobre el simbolismo esotérico de los números astronómicos y astrológicos de la novela, Davis escribe:

The number 13, which suggests «el dios solar en su posición cenital», becomes the key to the litany of Fedina de Rodas, abandoned in prison like Xbalanque in the underworld while the corn germinates, for she repeats thirteen times the Ora pro nobis, invoking not the Christian god but the thirteen gods of rain, with the sun god in the center of the sky and the twelve stars that integrate his personality around him ${ }^{2}$.

\footnotetext{
1 Pienso, por ejemplo, en La mala hora (Madrid: Talleres de Gráficos «Luis Pérez», 1962), «estropeada», según García Márquez, por un «corrector de estilo».

${ }^{2}$ Philologica pragensia, 13, 2 (1970), 103-04.
} 
El profesor Davis llega a esta conclusión citando, como su texto, la versión de la novela que aparece en las Obras escogidas (Madrid: Aguilar, 1964), donde Fedina Rodas sí repite la oración trece veces. Trece veces la repite también en la edición de Costa-Amic (1946) y en la de Losada (1948). Sin embargo, en la edición de Losada de 1952, que se sabe que Asturias revisó, y en las reimpresiones de esta edición, el Ora pro nobis aparece catorce veces. Aunque hay otros pasajes en la novela que parecen establecer una relación entre el número 13 y Fedina ${ }^{3}$, sin tener a mano el manuscrito de la tercera edición (Losada, 1952) es imposible averiguar si se trata de un cambio del autor o de un error tipográfico. La conclusión de Davis, entonces, probablemente válida, sigue dudosa ${ }^{4}$.

Lo que nos proponemos en estas páginas es dar alguos ejemplos de las diferencias que se encuentran entre las diversas ediciones de $\mathrm{El} \mathrm{Se}$ ñor Presidente. Esperamos que estos breves apuntes sirvan a la futura crítica tanto de esta novela como de las demás obras de Asturias, donde existe el mismo problema. Las ediciones que hemos comparado son las siguientes: a) 1. ${ }^{a}$ edición (México: Costa-Amic, 1946); b) 1. ${ }^{a}$ edición, en Obras escogidas (Madrid: Aguilar, 1955) ${ }^{5}$; c) 2. $^{\text {a }}$ edición (Buenos Aires: Losada, 1948), y d) 3. a edición (Buenos Aires: Losada, 1952). Además, cuando sea oportuno, nos referiremos a la $3 .^{a}$ impresión (1959) y a la 7. impresión (1967) de esta última edición ${ }^{6}$.

\section{ERRORES TIPOGRÁFICOS}

Comenzando con lo más obvio, se puede notar que hay errores tipográficos en todas las ediciones. La versión en las Obras escogidas, sin

${ }^{3}$ Poco antes de comenzar su letanía, Fedina ve en las paredes de su celda, entre otras cosas, «un número 13 sobre un testículo monstruoso». En el capítulo XXIII, el Presidente recibe una carta de Mónica Predomino, «enferma en el Hospital General, en la cama N. 14», que está "pegada a la de la enferma Fedina Rodas». Así, la cama de ésta sería o número 13 o número 15.

' De paso, notamos que el profesor Davis pasa por alto que el número 13 también tiene valor simbólico para el cristianismo, siendo Jesucristo y los doce apóstoles contrapartes del dios solar y las doce estrellas que complementan su personalidad.

${ }_{5}^{5}$ Aunque hay unas pequeñas diferencias, una comparación detallada nos convence de que la versión de las Obras escogidas es la primera edición (Costa-Amic, 1946). Las diferencias se pueden atribuir a errores tipográficos de la editorial Aguilar.

- Seguimos el sistema norteamericano, y no el español, para indicar las diversas ediciones y reimpresiones. 
embargo, es la que manifiesta el mayor descuido. No sólo se repiten los errores de la edición de Costa-Amic -errores que, en la mayor parte, se corrigieron en las otras ediciones-, sino que se añaden otros, tal como: «... a ver si se treve a negarlo...» (p. 200). Por otra parte, la reimpresión de Losada de 1967 parece ser la más cuidada. No obstante, si se han corregido los errores de las ediciones anteriores, aparecen algunos nuevos, tal como: «... risa chillonas...» (p. 8). Aunque el lector puede salvar los errores de este tipo, el mero hecho de que existan perjudica el valor de todas las ediciones y hace más difícil determinar quién sea el verdadero «autor» de las otras diferencias que encontramos.

Además, tomando en cuenta la predilección de Asturias por la repetición de frases y palabras y por la jitanjáfora, tal vez sea de esperar que haya distintas versiones de estos juegos de palabras y que representen, en su mayor parte, errores tipográficos. De algunos de los muy citados ejemplos de la jitanjáfora asturiana, por ejemplo, hay tres y hasta cuatro versiones ${ }^{7}$. Aunque estas diferencias puedan considerarse superficiales, para quien se interesa en la jitanjáfora asturiana $\mathrm{o}$, como hemos visto, sobre su posible relación con un simbolismo numérico, es importante tener en cuenta que existen.

\section{EsTILO DE PUNTUACIÓN}

En rigor, la tercera edición (Losada, 1952) revela que, al revisar la novela, Asturias se ocupó principalmente de la puntuación. Los cambios de puntuación entre la primera y segunda edición, por una parte, y la tercera, por otra, llegan a más de mil. La falta de comas y el uso de la coma en vez del punto y coma, guión o elipsis en la primera y en la segunda edición disminuyen notablemente la calidad poética de la novela. A veces encontramos tanto un sutil cambio en la tonalidad como en el sentido, como en las tres versiones del siguiente ejemplo: «A su voz sobrevino un silencio helado, luego luego una queja...» (Costa-Amic, p. 16; Aguilar, p. 200); "A su voz sobrevino un silencio helado, luego una queja...» (Losada, 1948, p. 19), y «A su voz sobrevino un silencio helado; luego... luego una queja...» (Losada, 1952, p. 18).

${ }^{7}$ Véanse, por ejemplo, las diversas versiones de la jitanjáfora que comienza «la car-car-car-car-carcajada...» (Costa-Amic, p. 9; Aguilar, p. 192; Losada, 1948, p. 13; Losada, 1952, p. 11; Losada, 1959, 1967, p. 9). 


\section{AÑADIDURAS, TACHADURAS O CAMBIOS DE ÍNDOLE MENOR}

Hay más de trescientas diferencias de este tipo. La mayoría de los cambios aparecen en la tercera edición (Losada, 1952), lo que sugiere que son obra del propio autor. Algunos indican un deseo de mejorar o corregir la gramática o la sintaxis (lo que también pudo haber sido obra de un corrector); otros cambian sutilmente una imagen o añaden un pequeño detalle. Así, «... palabritas de gusto...» (CostaAmic, p. 9; Losada, 1948, p. 12; Aguilar, p. 191) aparece también como «... palabritas de mal gusto...» (Losada, 1952, p. 11). Cuando el Pelele huye, en tres ediciones lo hace «por las calles intestinas en las salidas de la ciudad...» (Costa-Amic, p. 18; Losada, 1948, p. 20; Aguilar, p. 202) y también "por las calles intestinales, estrechas y retorcidas de los suburbios de la ciudad...» (Losada, 1952, p. 20). Al sugerir que el Presidente también vivía del temor, en tres ediciones se lee que «habitaba muchas casas a la vez...» (Costa-Amic, p. 11; Losada, 1948, p. 14; Aguilar, p. 194), mientras en otra se lee que «habitaba en las afueras de la ciudad muchas casas a la vez...» (Losada, 1952, p. 13).

A veces notamos lo que pudiera haber sido un esfuerzo para depurar el lenguaje de regionalismos. Así, «... los pequeños pegados a los senos tilintes...» (Costa-Amic, p. 13; Losada, 1948, p. 15; Aguilar, p. 195) se cambia a «... los pequeños pegados a los senos colgantes...» (Losada, 1952, p. 14). Claro que la palabra tilinte (elegante) disminuye el efecto de la patética escena en que se encuentra: la de «grupos de mujeres descalzas, con el canasto del desayuno en la hamaca de las naguas tendidas de rodilla a rodilla y racimos de hijos...». Sin embargo, tilinte aquí tiene cierta gracia irónica que le falta a colgante, y no se puede eliminar la posibilidad de que sea un cambio de un «corrector».

Lo mismo acontece en el siguiente diálogo entre Mr. Gengis, el norteamericano, y un amigo, quienes discuten, en un bar, la realidad guatemalteca:

-Entonces allá con ustedes no se conocen las caulas o tustes.

- Oh no, absolutamente, todo lo que estar caula ya está en la Biblia divinamente!

(Costa-Amic, p. 272; Losada, 1948, p. 236) ${ }^{8}$.

-Entonces allá, con ustedes, no se conocen los cuentos...

${ }^{8} \mathrm{La}$ versión de las Obras escogidas es ésta, pero se intercala un «¿Otro whisky?» entre las dos locuciones. 
-iOh, no, absolutamente; todo lo que estar cuento ya está la Biblia divinamente!

(Losada, 1952, p. 265.)

Nos preguntamos si caula (engaño, treta) y tuste (embuste) no expresan mucho mejor que cuento la obra del Presidente, ¿o es de suponer que Mr. Gengis, siendo norteamericano, desconociera los regionalismos?

En un ejemplo al menos se puede sospechar que la versión de Aguilar sufrió la corrección de un censor español. Bien se sabe que Asturias critica severamente, si no la religión, sí la forma que había asumido en su país. Como ha escrito Seymour Menton, «su cinismo llega al punto de transformar a Jesucristo en Jesupisto en boca del Mosco" ${ }^{9}$, cinismo mitigado en la edición de Aguilar, la única en que el «iJesupisto me valga!» del Mosco aparece como «iJesucristo me valga!» (p. 197).

\section{AÑADIDURAS, TACHADURAS O CAMBIOS DE MAYOR CUUANTÍA}

Hay unas veinte diferencias que pondríamos en esta categoría. Será suficiente mencionar cinco. La primera es el epígrafe tomado del Popol$V u h$ («... entonces se sacrificó a todas las tribus ante su rostro»), suprimido en la tercera edición (Losada, 1952) y en las reimpresiones de ésta. Ya que varios críticos ven una relación importante entre el Popol-Vuh y El Señor Presidente, sería interesante saber quién suprimió el epígrafe y por qué.

La segunda ocurre en el capítulo III, durante la fuga del Pelele. Entre los gritos de «... Erre, erre, erre...», la tercera edición (Losada, 1952) añade la frase «iI-N-R-Idiota! iI-N-R-Idiota!». ( $\left.p_{i} 22\right)$, estableciendo claramente al idiota como el Cristo que anda perdido: en este mundo de tinieblas, perseguido por «los clavos de una lluvia fina», mientras se defiende «de los postes del telégrafo».

Otro cambio que nos parece importante ocurre en el capítulo XXIII. Se trata de una carta recibida por el Presidente que se suprime en la tercera edición (Losada, 1952) y en las reimpresiones de ésta:

17. León Timoteo Ruiz, sirviente en casa del señor H. D. Edwars Jr., informa confidencialmente que se encuentra en esta capital un agente secreto norteamericano, investigando lo que hay de cierto en la participación del General Canales y Carvajal, en el asesinato del Portal del Señor.

'Historia crítica de la novela guatemalteca' (Guatemala: Edit. Universitaria, 1960), 199-200; reimpr. en Homenaje a Miguel Angel Asturias, ed. Helmy F. Giacoman (New York: Las Américas, 1971), p. 80. 
La omisión de esta carta nos parece extraña porque este capítulo, que por medio de las cartas recibidas por el Presidente revela muy bien las caulas y tustes del gobierno, ya anuncia el trágico destino de Miguel Cara de Angel. ¿No se sugiere aquí que el embuste de enviar a Miguel a los Estados Unidos fue un plan de un agente norteamericano? Notemos, por ejemplo, que el número de la carta (17) ya prefigura el número del camarote en el cual Miguel debe partir para Nueva York y también el número de la celda de la cárcel en que morirá ${ }^{10}$. ¿Por qué, entonces, habría querido Asturias tachar esta carta, en particular cuando complementa la estructura numérica?

Por fin, queremos mencionar, sin citarlas porque resultarían demasiado largas, que existen dos versiones del «poema de las generaciones sacrificadas» que «masculla» el estudiante en el capítulo XXVIII y tres versiones del muy comentado «Baile de Tohil». Ya que estas versiones se diferencian bastante, y no tratan sencillamente de añadiduras o tachaduras, tal vez representan los únicos cambios que se pueden atribuir a Asturias sin ninguna duda ${ }^{11}$.

De todos modos, como se puede ver, aunque El Señor Presidente lleva como fecha al pie de la página final de todas las ediciones: «Guatemala, diciembre de 1922; París, noviembre de 1925 y 8 de diciembre de 1932», es evidente que Asturias siguió revisando su novela. Al mismo tiempo, aunque Asturias indicó en varias entrevistas que había revisado la tercera edición (Losada, 1952), no se la puede aceptar como la edición definitiva. En conclusión, el estudio de esta novela requiere un análisis de las tres ediciones y también de las reimpresiones que se publicaron mientras Asturias aún vivía. En rigor, aunque resulte más fastidioso, el análisis de las diversas ediciones es una tarea con la cual debemos enfrentarnos, no importa cuál sea la obra, si no queremos menoscabar no sólo la crítica, sino también la literatura que criticamos.

\section{Oregon State University.}

RAY VERZASCONi

\footnotetext{
10 Véase el ya citado estudio del profesor Davis (p. 104) para un comentario sobre el significado del número 17.

${ }^{11} \mathrm{La}$ primera versión del «poema de las generaciones sacrificadas» aparece en Costa-Amic, 214-15; Losada, 1948, 188-89, y Aguilar, 425-26; la segunda, en Losada, 1952, 210-11. En cuanto al "Baile de Tohil», una versión aparece en las ediciones de Costa-Amic y Aguilar, otra en la segunda edición de Losada (1948) y la tercera en Losada (1952).
} 